\title{
Anaesthetic management of a case of giant cerebral aneurysm with persistent hypoglossal artery
}

\author{
Prakash C. Bharamagoudar, Joseph N. Monteiro, Ratan R. Chelani, Shwetal U. Goraksha
}

\begin{abstract}
The persistent hypoglossal artery is a rare carotid basilar anastomosis associated with hypoplastic or absent vertebral arteries. We report a case of clipping of a $2.5 \mathrm{~cm}$ size giant aneurysm just distal to the persistent hypoglossal branch, using intra-arterial balloon occlusion and adenosine induced near flow arrest method. It was an anaesthetic challenge to maintain haemodynamic and homeostatic equilibrium throughout the procedure.
\end{abstract}

Key words: Adenosine, giant aneurysm, intra-arterial balloon occlusion, persistent hypoglossal artery

\section{INTRODUCTION}

Intracranial aneurysms are present in roughly $5 \%$ of the population but are mainly asymptomatic. ${ }^{[1]}$ The treatment options when a patient develops neuro deficits, or subarachnoid haemorrhage are surgical clipping or endovascular embolisation of an aneurysm. Clipping of an aneurysm is challenging when there are branches arising just proximal or distal to an aneurysm and if it is a giant aneurysm. Advances in anaesthetic and surgical management, such as induced deep hypothermic circulatory arrest, application of temporary clips and endovascular balloon inflation techniques have improved the outcomes.

We report the anaesthetic management of a giant aneurysm of supraclinoid internal carotid artery (ICA), with proximally arising persistent hypoglossal

Department of Anesthesiology, P.D. Hinduja National Hospital and Medical Research Centre, Mumbai, Maharashtra, India

Address for correspondence:

Dr. Prakash C. Bharamagoudar, Department of Anesthesiology,

P.D. Hinduja National Hospital and Medical Research Centre,

Mumbai, Maharashtra, India.

E-mail: drprakashcb@gmail.com

\begin{tabular}{|l|l|}
\hline \multicolumn{2}{|c|}{ Access this article online } \\
\hline Quick Response Code: & Website: \\
\hline & www.jnaccjournal.org \\
\cline { 2 - 2 } & \\
\hline & \\
\hline
\end{tabular}

artery (PHA), by intra-arterial balloon occlusion and adenosine induced near flow arrest. The PHA is a rare carotid-basilar anastomosis with a reported incidence between $0.03 \%$ and $0.26 \%$ on cerebral angiography. ${ }^{[2]}$ Both vertebral arteries are absent or hypoplastic in these cases. It is important to clip the aneurysm carefully without affecting the posterior circulation. It is an anaesthetic challenge to maintain haemodynamic and homeostatic equilibrium throughout the procedure.

\section{CASE REPORT}

A 55-year-old female patient weighing $80 \mathrm{~kg}$ presented with blurring of vision in right eye since 1-year which was insidious in onset and non-progressive. Significantly, she complained of frequent headaches since 2 months and was recently diagnosed as a hypertensive and was on amlodipine. Her general and systemic examination was normal.

Her computed tomography (CT) and magnetic resonance (MR) angiogram showed a $2.5 \mathrm{~cm}$ aneurysm of the right supraclinoid ICA. There was evidence of PHA arising from right high cervical ICA [Figure 1] which was coursing through the right hypoglossal canal

This is an open access article distributed under the terms of the Creative Commons Attribution-NonCommercial-ShareAlike 3.0 License, which allows others to remix, tweak, and build upon the work non-commercially, as long as the author is credited and the new creations are licensed under the identical terms.

For reprints contact: reprints@medknow.com

How to cite this article: Bharamagoudar PC, Monteiro JN, Chelani RR, Goraksha SU. Anaesthetic management of a case of giant cerebral aneurysm with persistent hypoglossal artery. J Neuroanaesthesiol Crit Care 2016;3:265-7. 


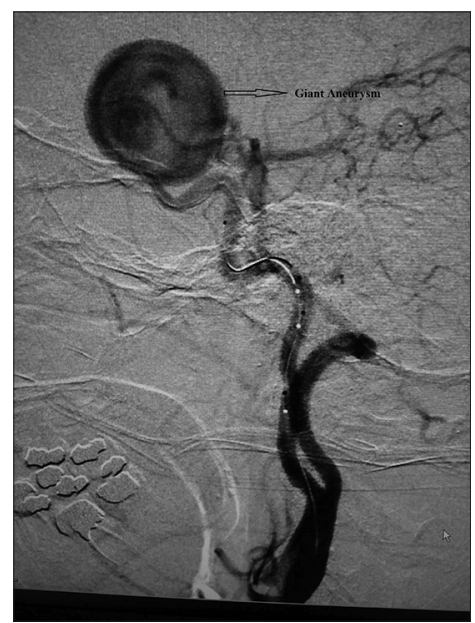

Figure 1: Angiogram showing giant internal carotid artery aneurysm with persistent hypoglossal branch

to form basilar artery (BA). Both vertebral arteries were hypoplastic and did not form BA.

Other investigations electrocardiogram, echocardiography and stress test were normal. There was no evidence of ischemic heart disease or coronary artery disease. Haematological investigations were normal. An elective craniotomy and clipping of an aneurysm was planned. On the day prior to surgery intra-arterial balloon occlusion test of the ICA was done in the digital subtraction angiography (DSA) suite under local anaesthesia. This test was done to check and document adequate collateral circulation before performing any permanent intervention. The patient tolerated occlusion of the ICA clinically for $45 \mathrm{~min}$ without any neuro deficits.

On day of surgery, in the DSA suite, the patient was premedicated with injection midazolam $1.5 \mathrm{mg}$. Induced with fentanyl citrate $2 \mu \mathrm{g} / \mathrm{kg}$, propofol $2 \mathrm{mg} / \mathrm{kg}$, atracurium besylate $0.75 \mathrm{mg} / \mathrm{kg}$ and intubated with a cuffed endotracheal tube no 7. General anaesthesia was maintained with a mixture of $50 \%$ air and oxygen with sevoflurane $0.5 \mathrm{MAC}$, muscle relaxation atracurium besylate $0.5 \mathrm{mg} / \mathrm{kg} / \mathrm{h}$ and propofol $4-6 \mathrm{mg} / \mathrm{kg} / \mathrm{h}$ as a titrated infusion. The left radial artery was cannulated. The left internal jugular venous (IJV) cannulation was attempted under ultrasonography (USG) guidance. Both USG and fluoroscopy showed narrowing of left IJV when trying to cannulate. It was decided to opt for femoral venous access. Arterial sheaths were introduced in both femoral arteries. Through the right femoral arterial sheath, angiogram was performed and the balloon was placed just proximal to the aneurysm but distal to the PHA [Figure 2]. Anticoagulation was maintained with heparin 2000 units and activated clotting time (ACT) maintained at $350 \mathrm{~s}$. The patient was monitored with pulse oximetry, arterial invasive pressure, capnogram, urine output, temperature and five lead electrocardiograms.

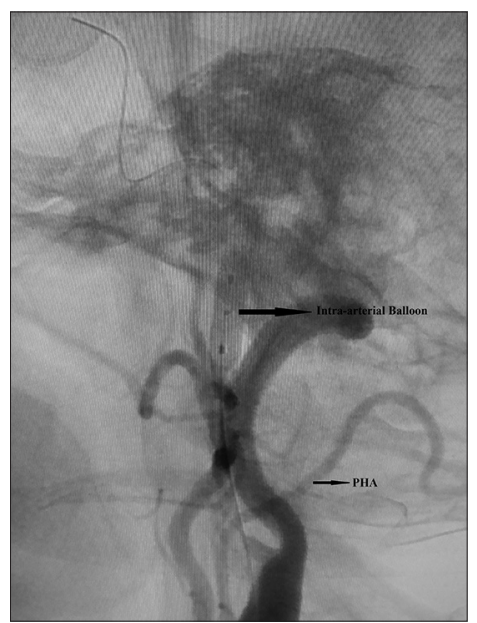

Figure 2: Angiogram showing intra-arterial balloon occlusion distal to hypoglossal branch

The patient was electively ventilated and transported to the operation theatre. Due to the prospect of using adenosine induced near flow arrest intra-operatively, transcutaneous pacing pads were applied. Defibrillator, emergency drugs and transvenous pacing facilities kept ready in case of emergency. Somatosensory evoked potential monitoring was done to detect any ischemic insult. Throughout the surgery, the end tidal $\mathrm{CO}_{2}$ was maintained between 28 and $30 \mathrm{~mm}$ of $\mathrm{Hg}$, urine output $1 \mathrm{~mL} / \mathrm{kg} / \mathrm{h}$, ACT $300-350 \mathrm{~s}$ and temperature $35-35.5^{\circ} \mathrm{C}$. Propofol was used for maintaining anaesthesia as it has neuroprotection properties.

Interventional neuroradiologist was present throughout the procedure and position of the balloon was checked at each step under fluoroscopy. Before the clipping, the intra-arterial balloon was inflated and the ICA occluded to decompress and reduce the size of the aneurysm after which the aneurysm was aspirated. However the aneurysm continued to fill. Adenosine boluses to a maximum dose of $0.4 \mathrm{mg} / \mathrm{kg}$ were given for temporary flow arrest and the surgeon applied the clip. The balloon was deflated and an intra-operative angiogram was done, which demonstrated there was no filling of the right ICA but the PHA was filling normally. Heparin was reversed with protamine and ACT brought down to $149 \mathrm{~s}$. Haemostasis was achieved and the balloon withdrawn. Isotonic crystalloids $1.5 \mathrm{~L}$ and $600 \mathrm{~mL}$ packed red blood cells were administered throughout the procedure. Total duration of procedure was $8 \mathrm{~h}$. The post-operative haemoglobin was $9.8 \mathrm{~g} \%$. At the end of surgery, we reversed and awaken the patient. Neurological assessment was done and it was normal. Due to the complex nature of case, prolonged surgery it was jointly decided to electively ventilate the patient. Next day, the patient developed left sided stroke which delayed weaning. The patient was extubated on $7^{\text {th }}$ day. The patient was transferred from the Intensive Care Unit 
to the ward on $10^{\text {th }}$ day and discharged from the hospital on $20^{\text {th }}$ day.

\section{DISCUSSION}

A PHA is the second most common vascular anomaly involving the carotid basilar anastomosis, next to the persistent trigeminal artery. The PHA arises from the cervical part of ICA above the level of C3. It enters the posterior fossa via hypoglossal canal. Vertebral arteries may be absent or hypoplastic and hence the posterior circulation, mainly brainstem and cerebellum are supplied by the PHA only. ${ }^{[2,3]}$

Due to the altered flow dynamics and anomalous structure of vessel wall, atheromatous plaques and aneurysms formations are reported in PHA, BA or ICA. ${ }^{[3,4]}$ These kind of aneurysms are difficult to treat surgically because of their location, size and difficulty in preserving PHA flow.

Apart from surgical clipping other treatment options are endovascular coiling (stent assisted or balloon-assisted) or flow diversion. ${ }^{[1]}$ We treated the ICA an aneurysm by surgical clipping but instead of using temporary clamps or flow diversion we used DSA guided intra-arterial balloon occlusion. This was important to maintain PHA blood flow.

Intra-operative aneurysm rupture is a devastating complication and is exteremely challenging for the surgeon to apply clip in a bleeding surgical field. Adenosine induced temporary flow arrest has been shown to enhance the feasibility and safety of clipping in intra-operative aneurysmal bleeding. ${ }^{[5,6]}$

Adenosine is a nucleoside that occurs naturally throughout the body. Its half-life is $<10 \mathrm{~s}$ in blood. It acts by inward rectifier $\mathrm{K}^{+}$current and inhibition of calcium current. The results of these actions are marked hyperpolarisation and suppression of calcium-dependent action potentials. When given as a bolus dose, adenosine directly inhibits atrioventricular (AV) nodal conduction, sometimes AV block but has lesser effects on sinoatrial node. ${ }^{[7]}$

Retrospective reviews by Bendok et al. ${ }^{[5]}$ and Guinn et al. ${ }^{[8]}$ both demonstrated that adenosine induced flow arrest is very effective method for surgical clipping in ruptured, non-ruprtured, giant and other surgically difficult aneurysms. Adenosine has been used effectively in various difficult aneurysmal surgeries for successful clipping. ${ }^{[9,10]}$
Aneurysms in carotid basilar anastomotic vascular malformations can be diagnosed with MR angiogram, CT scan and DSA. These can be treated by either endovascular coiling ${ }^{[11]}$ or surgical clipping. A proper understanding of the anatomy and physiology of the brain, protection of the posterior circulation, cerebral protection, continuous monitoring and maintaining transmural pressure gradient by maintaining stable haemodynamics are essential for successful anaesthetic management.

\section{Financial support and sponsorship} Nil.

\section{Conflicts of interest}

There are no conflicts of interest.

\section{REFERENCES}

1. Seibert B, Tummala RP, Chow R, Faridar A, Mousavi SA, Divani AA. Intracranial aneurysms: Review of current treatment options and outcomes. Front Neurol 2011;2:45.

2. Chaljub G, Guinto FC Jr, Crow WN. Persistent hypoglossal artery: MRI and MRA findings. J Comput Assist Tomogr 1995; 19:668-9.

3. Kanai H, Nagai H, Wakabayashi S, Hashimoto N. A large aneurysm of the persistent primitive hypoglossal artery. Neurosurgery 1992;30:794-7.

4. De Caro R, Parenti A, Munari PF. The persistent primitive hypoglossal artery: A rare anatomic variation with frequent clinical implications. Ann Anat 1995;177:193-8.

5. Bendok BR, Gupta DK, Rahme RJ, Eddleman CS, Adel JG, Sherma AK, et al. Adenosine for temporary flow arrest during intracranial aneurysm surgery: A single-center retrospective review. Neurosurgery 2011;69:815-20.

6. Owall A, Gordon E, Lagerkranser M, Lindquist C, Rudehill A, Sollevi A. Clinical experience with adenosine for controlled hypotension during cerebral aneurysm surgery. Anesth Analg 1987;66:229-34.

7. Joseph RH, Augustus OG. Agents used in cardiac arrhythmias. In: Katzung BG, editor. Basic and Clinical Pharmacology. $12^{\text {th }}$ ed. McGraw Hill Medical; 2012.

8. Guinn NR, McDonagh DL, Borel CO, Wright DR, Zomorodi AR, Powers CJ, et al. Adenosine-induced transient asystole for intracranial aneurysm surgery: A retrospective review. J Neurosurg Anesthesiol 2011;23:35-40.

9. Nussbaum ES, Sebring LA, Ostanny I, Nelson WB. Transient cardiac standstill induced by adenosine in the management of intraoperative aneurysmal rupture: Technical case report. Neurosurgery 2000;47:240-3.

10. Groff MW, Adams DC, Kahn RA, Kumbar UM, Yang BY, Bederson JB. Adenosine-induced transient asystole for management of a basilar artery aneurysm. Case report. J Neurosurg 1999;91:687-90.

11. Grand M, Nepper-Rasmussen J. Aneurysm of persistent primitive hypoglossal artery occluded with guglielmi detachable coils. Interv Neuroradiol 2005;11:247-50. 